\title{
STUDI META ANALISIS PENGARUH KEPEMIMPINAN TERHADAP BUDAYA ORGANISASI PADA LEMBAGA PENDIDIKAN DI INDONESIA
}

\author{
Dedi Purwana E.S. \\ Fakultas Ekonomi Universitas Negeri Jakarta \\ dpurwana@unj.ac.id
}

\begin{abstract}
The studyaims to examine the influence of leadership on organizational culture at Indonesian education institutions. It was conducted from April to October 2015. Meta-analysis approach was used to study of the 12 research publications related to the examined variables. These correlational researches were conducted in 20102015. The data was retrieved from two public higher education libraries in Indonesia. The study concluded that leadership had directy effect on organizational culture. The result of meta-analysis indicates that average of correlation coefficient $(\bar{r})$ is 0,573 with standard deviation equals 0,101565 and corrected correlation $\left(r_{c}\right)$ Values 0,623. The differences of the 12 correlations coefficient are caused by sampling error $\left(\hat{o}^{2}{ }_{e}\right)=0,006749$ with variance estimation $\left(\sigma_{P}^{2}\right)=0,01061$.
\end{abstract}

Keywords: Leadership, organizational culture and meta-analysis.

\begin{abstract}
ABSTRAK
Penelitian untuk menguji pengaruh kepemimpinan terhadap budaya organisasi di institusi pendidikan Indonesia. Hal ini dilakukan dari bulan April sampai Oktober 2015. Pendekatan metodologi digunakan untuk mempelajari 12 publikasi penelitian yang berkaitan dengan variabel yang diteliti. Penelitian korelasional ini dilakukan di 2010-2015. Data diambil dari dua perpustakaan perguruan tinggi negeri di Indonesia. Penelitian ini menyimpulkan bahwa kepemimpinan berpengaruh langsung terhadap budaya organisasi. Hasil meta-analisis menunjukkan bahwa rata-rata koefisien korelasi $(\bar{r})$ adalah 0,573 dengan standar deviasi sama dengan 0,101565 dan korelasi terkoreksi $(\mathrm{rc})$ sebesar 0,623 . Perbedaan 12 koefisien korelasi tersebut disebabkan oleh kesalahan sampling $\left(o^{2} e\right)=0,006749$ dengan estimasi varians $\left(\sigma_{P}^{2}\right)=0,01061$.
\end{abstract}

Kata kunci: Kepemimpinan, budaya organisasi dan meta-analisis. 


\section{PENDAHULUAN}

Era globalisasi sekarang ini, menuju perubahan yang begitu cepat dan komplek yang terjadi secara terus menerus tanpa henti dalam beberapa dekade terakhir ini. Dampak perubahan tersebut terjadi pada semua bidang, termasuk pada bidang pendidikan. Proses transformasi pendidikan yang sedang berlangsung bergerak begitu sangat cepat dengan instan. Keberhasilan melaksanakan transformasi kelembagaan berbeda antara satuan pendidikan. Lingkungan internal dan ekternal merupakan faktor-faktor yang mempengaruhi kemampuan satuan pendidikan beradaptasi terhadap perubahan.

Karakteristik pembeda antara satu satuan pendidikan dibandingkan organisasi lainnya terletak pada budaya organisasi yang dimiliki. Kompleksitas budaya organisasi dipengaruhi oleh beberapa faktor seperti ukuran organisasi, sektor industri dimana organisasi berkiprah, siklus hidup organisasi tersebut-baru (introduction), berkembang (growth), dewasa (mature) atau penurunan (decline). Dengan demikian dapat dikatakan bahwa dari perspektif ukuran maka semakin besar organisasi, akan semakin komplek budaya yang dimilikinya.

Pemimpin yang memahami dengan baik mengenai kompleksitas budaya pada organisasi memudahkan dalam penyusunan strategi perubahan yang tepat sebagai antisipasi tekanan lingkungan eksternal. Kepemimpinan juga memberikan kontribusi terhadap budaya organisasi perguruan tinggi dalam kerangka implementasi tata kelola yang baik (Good Governance). Beberapa penelitian mengungkapkan bahwa budaya organisasi yang kondusif dapat mempertahankan bahkan meningkatkan kinerja organisasi.

Untuk membangun good governance, institusi pendidikan harus memiliki kepemimpinan yang kuat (strong leadership) dan efektif yang dapat mempengaruhi seluruh perilaku individu dan kelompok yang terkait dalam pencapaian tujuan, sasaran, institusi dengan mengikuti nilai, norma, etika, dan budaya organisasi yang disepakati bersama. Kepemimpinan yang kuat adalah kepemimpinan yang visioner sehingga mampu merumuskan dan mengartikulasi visi yang realistik, kredibel, dan menarik tentang masa depan yang menekankan keharmonisan hubungan manusia dan mampu menstimulasi anggotanya secara intelektual dan arif untuk mewujudkan visi dan misi organisasi, serta mampu memberikan arahan, tujuan, peran dan tugas kepada seluruh unsur terkait.

Banyak literatur organisasi, manajemen dan literatur administrasi pendidikan menggambarkan kepemimpinan sebagai bagian integral dari efektivitas pengelolaan lembaga pendidikan. Kualitas dari pemimpin seringkali dianggap sebagai faktor terpenting yang menentukan 
keberhasilan atau kegagalan organisasi. Untuk menjadi pemimpin yang efektif, misalnya seorang Rektor/ Dekan/ ketua program studi harus dapat mempengaruhi seluruh tenaga pendidik dan kependidikan yang dipimpinnya melalui cara-cara yang positif untuk mencapai tujuan pendidikan.

Penelitian tentang pengaruh
kepemimpinan terhadap budaya organisasi di lembaga pendidikan telah banyak dilakukan. Hasil-hasil penelitian secara umum menyimpulkan bahwa kepemimpinan berpengaruh langsung secara positif terhadap budaya organisasi. Namun demikian, tidak sedikit hasil penelitian yang membuktikan kesimpulan sebaliknya. Hal ini tentu menyulitkan bagi peneliti selanjutnya untuk menarik kesimpulan terhadap variabel penelitian yang sama tersebut dalam waktu dan tempat penelitian yang berbeda, terutama bagi penelitian ilmu-ilmu sosial.

Keadaan sebagaimana disebutkan tentu saja menimbulkan masalah terutama dalam mengkonstruksi suatu teori yang komprehensif atau menjadikannya sebagai landasan pengambilan putusan. Oleh karena itu, peneliti tertarik untuk mengetahui konsistensi hasil penelitian yang telah dilaksanakan terkait variabel kepemimpinan dan budaya organisasi pada lembaga pendidikan di Indonesia dengan pendekatan meta-analisis.

\section{KAJIAN TEORITIK \\ Kepemimpinan}

Salah satu faktor penentu kesuksesan organisasi baik sektor publik maupun swasta adalah kepemimpinan. Hughes (2009) mendeskripsikan Leadership is often more associated with words like risk taking, dynamic, creativity, change, and vision. Some say leadership is fundamentally a value choosing, and thus a value leader, activity, whereas management is not. Leaders are thought to do the right things, whereas managers are thought to do things right. Weihrich dan Koontz (2005) menyatakan bahwa leadership is the art or process influencing people so that they will strive willingly and enthuasiastically toward the achievement of group goals. Dengan kata lain kepemimpinan merupakan seni atau proses mempengaruhi orang lain sehingga mereka berjuang dengan rela dan antusias untuk pencapaian tujuan-tujuan kelompok.

Senada dengan pendapat di atas, Amstrong (2009:4)menyatakan bahwa leadership is the process of getting people to do their best to achieve desired result. It involves developing and communicating a vision for the future, motivating people and gaining their engagement. Yulk (2010:26) mendefinisikan kepemimpinan sebagai the process of influencing others to understand and agree about what needs to be done and how to do it, and the process of facilitating individual and collective efforts to accomplish shared 
objectives. Selanjutnya, Daft (2008) menyatakan Leadership is influence relationship among leader and follower who intend real changes and outcomes that reflect their shared purposes. Menurut Daft (2008), dalam literatur teori kepemimpinan, terdapat beberapa pendekatan untuk meng-analisa apa, siapa dan bagaimana ke-pemimpinan, di antaranya: a) Pendekatan berdasarkan Great Man theory; b) Pendekatan berdasarkan ciri dan sifat pemimpin (the trait approach); c) Pendekatan berda-sarkan perilaku pemimpin (behavior approach); d) Pendekatan berda-sarkan kontingensi (contingency ap-proach); Pendekatan berda-sarkan pengaruh (influence ap-proach); danf) Pendekatan berda-sarkan hubungan (relational approach).

\section{Kepemimpinan Pendidikan}

Organisasi pendidikan memerlukan kepemimpinan kuat. Kepemimpinan pendidikan adalah pemimpin pada satu lembaga satuan pendidikan.Tanpa kehadiran kepemimpinan pendidikan, proses pendidikan termasuk pembelajaran tidak akan berjalan efektif. Bush dan Middlewood (Bush, 2005) berpandangan bahwa there is convincing evidence that successful leaders focus most strongly on motivating and developing people rather than establishing and main-taining systems and structures. The latter is important but should always be a second-order priority. In education, as in many other settings, people are most likely to show commitment if they are valued by those who have responsibility for them. This applies to teachers just as much as to the children and students. It also applies to the many support staff who work in schools and colleges. An inclusive approach, involving all categories of staff, is most likely to produce the teamwork which is also a feature of successful organisations.

Beberapa penelitian mengungkapkan bahwa kepemimpinan transformasional efektif diterapkan di lembaga pendidikan. Menurut Colquitt, Lepine, dan Wesson (2015), "transfor-mational leadership involves inspiring followers to commit to a shared vision that provides meaning to their work also serving as a role model who helps followers develop their own potential and view problems from new perspectives."

Dari sisi proses, kepemimpinan transformasional menurut Mullins (2010), "...is a process of engendering higher level of motivation and commitment among followers. The emphasis is on generating a vision for the organization and the leaders ability to appeal to higher ideals and value followers, and creating a feeling of justice, loyalty and trust." Pendapat tersebut sejalan dengan pernyataan Ivancevich, Konopaske dan Matteson (2008) yang menjelaskan bahwa, Transformational leadership motivates followers to work for goal instead of short term self interest and for achievement and self 
actualizations instead of security; is able to express a clear vision and inspire other to strive to accomplish the vision. Robbins dan Judge (2007) juga menegaskan bahwa kepemimpinan transformasional adalah pemimpin yang menginspirasi pengikut untuk menanggalkan kepentingan sendiri, pemimpin yang mampu menghasilkan efek luar biasa pada pengikut, demikian argumen Robbins dan Judge.

Daft (2008) menyatakan bahwa "transformational Leadership is characterized by the ability to bring about significant change in both followers and the organization". Lebih lanjut Robbins dan Coulter (2009) menguraikan "in addition evidence indicates that transformational leadership is strongly correlated with lower-turnover rates and higher levels of productivity, employee satisfaction, creativity goal attainment, and follower well-being. Bass dan Riggio (2006) menyatakan bahwa "Transformational leaders are those who stimulate and inspire followers to both achieve extraordinary outcomes and, in the process, develop their own leadership capacity." Dalam kajiannya, Bass dan Riggio (2006) menguraikan empat komponen kepemimpinan transformasional, yaitu 1) Idealized Influence; 2) Inspirational Motivation; 3) Intellectual Stimulation; dan 4) Individualized Consideration.

Studi empirik tentang efektivitas kepemimpinan tranformasi di sektor pendidikan yang dilakukan
Neumann (1992) membuktikan bahwa kepemimpinan transformasional mampu mengatasi masalah stres terkait persoalan keuangan universitas dengan melibatkan partisipasi dosen dalam pengambilan keputusan.

Kazt pada tahun 1977 melakukan kajian terhadap 20 jurusan di dua universitas dan menyimpulkan bahwa kepemimpinan transaksional sangat efektif diterapkan pada saat konflik di dalam jurusan sangat tinggi dan sebaliknya kepemimpinan transformasional menjadi lebih efektif ketika tidak terdapat konflik di dalam jurusan-jurusan tersebut.

Studi yang dilakukan Aldyn Balyer (2012) menyimpulkan bahwa kepemimpinan transformasional membantu kepala sekolah membentuk sikap mereka dalam membawa kemajuan sekolah. Hal ini dikarenakan persepsi guru terhadap kepemimpinan transformasional kepala sekolah sangat positif. Studi ini juga menyimpulkan bahwa sikap kepala sekolah wanita dipan-dang lebih ramah dibandingkan kepala sekolah pria.

Korkmaz (2007) melakukan penelitian tentang pengaruh gaya kepemimpinan kepala sekolah, yaitu kepemimpinan transformasional dan transaksional, dan kepuasan kerja guru terhadap kesehatan organisasi sekolah. Sampel penelitian berjumlah 875 guru dan 46 sekolah menengah atas di kota Ankara Turki, dengan menggunakan metode survei. Kuesioner yang digunakan untuk 
mengukur gaya kepemimpinan kepala sekolah adalah Bass' Multi Factors Leadership Questionaire (MLQ). Hoy's Organizational Health Inventory $(\mathrm{OHI})$ digunakan untuk mengukur variabel kesehatan organisasi. Hasil penelitian yang berjudul The Effects of Leadership Styles on Organizational Health ini menyimpulkan bahwa kepemimpinan transformasional kepala sekolah berpengaruh langsung terhadap kepuasan kerja guru dan tingginya tingkat kepuasaan guru berdampak kepada kesehatan organisasi sekolah.

Smith (2009) mengkaji hubungan antara budaya organisasi, budaya sosial dan gaya kepemimpinan di lingkungan sekolah. Penelitian dalam bentuk disertasi PhD ini bertujuan mengidentifikasi hubungan antara budaya organisasi dan budaya sosial; identifikasi gaya kepemimpinan apakah yang paling efektif dalam pencapaian tujuan organisasi dengan menyeimbangkan kebutuhan-kebutuhan para pegawai yang terlibat; identifikasi isu-isu relevan terkait silang budaya yang dapat mempengaruhi gaya kepemimpinan; menentukan bagaimana gaya kepemimpinan berbeda dalam masyarakat multi kultur. Survei dilakukan dengan menggunakan Multifactor Leadership Questionnaire (MLQ) untuk mengukur skor Indealized influences, Inspirational Motivation, Intellectual Motivation dan Individualized consideration yang digagas Bass dan Avolio terhadap 23 kordinator pengawas kafetaria dan 106 manajer kafetarian SMA di distrik Miami-Dade county Florida. Hasil penelitian membuktikan bahwa terdapat hubungan secara signifikan antara gaya kepemimpinan, budaya organisasi dan keefektifan organisasi.

Dalam kerangka perguruan tinggi, Abbasi dan Zamani-Miandashti (2013) melakukan kajian tentang peranan kepemimpinan transformasional, budaya organisasi dan pembelajaran organisasi terhadap kinerja fakultas pertanian di Iran. Sampel penelitian sejumlah 329 dosen dari berbagai fakultas pertanian universitas negeri di Iran. Analisis data menggunakan Structural Equation Modelling (SEM) dengan software Lisrel 8.50. Hasil penelitian membuktikan bahwa terdapat hubungan yang positif dan signifikan antara komponen kontekstual (kepemimpinan transformasional dan budaya pembelajaran organisasi) dengan komponen proses (organisasi pembelajar). Penelitian membuktikan adanya hubungan yang positif dan signifikan antara komponen proses (organizational learning) dengan komponen kinerja. Dengan demikian, kepemimpinan transformasional dan budaya pembelajaran organisasi dengan pengaruh proses pembelajaran organisasi tidak hanya mampu meningkatkan kinerja fakultas tetapi juga merubah fakultas tersebut menjadi organisasi pembelajar. 


\section{Budaya Organisasi}

Para peneliti organisasi sudah lama melihat setiap organisasi memiliki budaya yang berbeda satu dengan lainnya meskipun mereka menjalankan fungsi yang sama. Satu organisasi dibandingkan organisasi lannya bisa saja lebih otoritarian atau demokratis; sangat terikat peraturan atau informal; inovatif atau menolak perubahan; bisa menerima keragaman atau anti-keragaman; atau bisa membawa atmosfer yang bersahabat atau tidak bersahabat. Daft (2008) medefinisikan budaya sebagai "the set of key values, assumptions, understandings, and norms that is shared by member of organization and taught to new members as a correct."

Menurut Kreitner dan Kinicki (Kreitner, 2011), "organizational culture is the set of shared, taken for granted implicit assumptions that a group holds and that determines how it perceives, thinks about and reacts to its various environment". Pendapat yangsama dikemukakan Jones (Jones, 2013),"organizational culture as the set of shared values and norms that control organizational members interactions with each other and with suppliers, customers and other people outside the organization". Heneman III, Judge dan Mueller (Heneman III, 2015) berpendapat bahwa budaya organisasi adalah topik yang sangat kompleks, sebagian karena budaya sangat sulit untuk diartikan.

http://journal.unj.ac.id/unj/index.php/jpeb
Senada dengan pendapatpendapat sebelumnya, Schein (Schein, 2010) menyatakan bahwa budaya organisasi defined as a pattern of shared basic assumptions learned by a group as it solved its problems of external adaptation and internal integration, which has worked well enough to be considered valid and, therefore to be taught to new members as the correct way to perceive, think, and feel in relation to those problems.

Dari berbagai definisi tentang budaya yang telah dipaparkan dapat disimpulkan bahwa budaya dapat diartikan sebagai pandangan hidup yang diakui bersama oleh suatu kelompok masyarakat yang mencakup cara berfikir, perilaku, sikap, nilai yang tercermin baik dalam wujud fisik maupun abstrak. Demikian juga budaya dapat dilihat sebagai suatu perilaku, nilai-nilai, sikap hidup, dan cara hidup untuk melakukan penyesuaian dengan lingkungan, dan sekaligus cara untuk memandang persoalan dan memecahkannya. Dengan demikian dapat dikatakan bahwa budaya merupakan suatu pola hidup menyeluruh bersifat kompleks, abstrak, dan luas.

Organisasi sebagai subkultur memiliki karakteristik khas berdasarkan elemen-elemen pembentuknya sebagaimana dikemukakan Joanne Martin (Luthans, 2011) As individual come into contact with organizations, they come into contact with dress norms, stories people tell what goes on, the organization's 
formal rules and procedures, its formal codes of behavior, rituals, task, pay system, jargon, and jokes only understood by insiders, and soon. These elements are some of the manifestations of organizational culture.

Menurut Kinicki dan Williams,"culture is transmitted to employees in several ways, most often throught such devices as symbols, stories, heroes, rites and rituals". Sejalan dengan pendapat tersebut, Mullins (2010) berpendapat bahwa "organizational culture is the collection of traditions, values, policies, beliefs and attitudes that constitute a pervasive context for everything we do and think in an organization". Senada dengan pendapat tersebut, Colquitt (Colquitt, 2015)menjelaskan budaya organisasi sebagai pengetahuan sosial bersama dalam sebuah organisasi mengenai aturan, norma-norma, nilai-nilai yang membentuk sikap dan perilaku karyawan.

\section{Meta Analisis}

Meta analisis adalah salah satu upaya untuk merangkum berbagai hasil penelitian secara kuantitatif. Meta analisis ditujukan untuk menganalisis kembali hasilhasil penelitian yang diolah secara statistika berdasar data primer. Terdapat beberapa teknik meta analisis, antara lain dikemukakan oleh Hedges dan Olkin; Rosenthal \& Rubin serta teknik yang terbaru yang dikemukakan oleh Hunter dan Smith
(Hunter, 2004). Teknik tersebut adalah teknik yang paling cermat dan teliti. Teknik ini menguji effectsize (sampling error), measurement error, reliabilitas variabel dependen, dan reliabilitas variabel independen. Sampling error yang dikaji dapat dipergunakan untuk mengkaji lebih lanjut pengaruhnya terhadap berbagai penelitian yang diteliti.

Terkait fungsi meta analisis, Borenstein, et.al., (2009) menyatakan bahwa meta-analyses are conducted for a variety of reasons, not only to synthesize evidence on the effects of interventions or to support evidencebased policy or practice. The purpose of the meta-analysis, or more generally, the purpose of any research synthesis has implications for when it should be performed, what model should be used to analyze the data, what sensitivity analyses should be undertaken, and how the results should be interpreted.

Hunter dan Schmidt (Hunter, 2004), menyebutkan sedikitnya ada 11 artifak yang dapat digunakan sebagai kriteria untuk memahami mengapa terdapat perbedaan hasil penelitian mengenai satu topik yang sama yang perlu dikoreksi. Artifakartifak tersebut adalah: (1) Kesalahan pengambilan sampel; (2) Kesalahan pengukuran pada variabel dependen; (3) Kesalahan pengukuran pada variabel independen; (4) Dikotomi pada variabel dependen; (5) Dikotomi pada variabel independen; (6) Variasi rentangan dalam variabel independen; (7) Artifak atrisi; 
Ketidaksempurnaan validitas konstruk pada variabel dependen; (9) Ketidaksempurnaan validitas konstruk pada variabel independen, (10) Kesalahan pelaporan atau trankripsional, dan (11) Varians yang disebabkan oleh faktor luar.

Adapun langkah-langkah yang harus ditempuh dalam meta-analisis meliputi proses sebagai berikut: (1) mengidentifikasi dan memformulasikan permasalahan penelitian; (2) mengumpulkan data melalui seleksi artikel atau hasil-hasil penelitian yang relevan dengan permasalahan penelitian; (3) menjelasan dan evaluasi data, dan (4) analisa dan interpretasi hasil analisa itu sendiri.

Secara garis besar, metaanalisis dilaksanakan dalam dua tahapan. Tahap pertama, bare-bone meta-analysis, yaitu meta analisis yang yang dimaksudkan untuk mengoreksi artifak-artifak yang informasinya tersedia pada hampir semua studi. Tahap kedua,metaanalisis yang dimaksudkan untuk mengoreksi artifakartifak yang informasinya hanya tersedia secara random atau sporadis.Jadi metaanalisis tetap dapat dilakukan dengan menggunakan distribusi efek artifak dan mengabaikan fakta bahwa ada salah satu atau beberapa informasi artifak yang tidak tersedia.Meta-analisis berbekal hasil analisis penelitian individual, baik penelitian korelasional maupun penelitian eksperimental.

Untuk mensintesis literatur riset, metaanalysis statistikal menggunakan hasil akhir dari studistudi yang serupa seperti ukuran efek, atau besarnya efek. Fokus pada ukuran efek dari penemuan empiris ini merupakan keunggulan metaanalysis dibandingkan dengan metode tinjauan literatur lain. Metaanalysismemungkinkan adanya pengkombinasian hasil-hasil yang beragam dan memperhatikan ukuran sampel relatif dan ukuran efek. Hasil dari tinjauan ini akurat mengingat jangkauan analisis ini yang sangat luas dan analisis yang terpusat.Metaanalysis juga menyediakan jawaban terhadap masalah yang diperdebatkan karena adanya konflik dalam penemuan-penemuan beragam studi serupa.

\section{METODOLOGI PENELITIAN}

Penelitian ini menggunakan metode kuantitatif dengan pendekatan meta analisis. Dalam penelitian ini ditentukan variabel kepemimpinan sebagai variabel bebas (independent) dan variabel budaya organisasi sebagai variabel terikat (dependent). Data dikumpulkan dengan mencari koleksi hasil penelitian yang dipublikasikan pada jurnall online proquest dan google scholar yang terbit mulai tahun 2010-2015 terkait variabel dalam penelitian ini. Penelusuran hasil penelitian juga dilakukan terhadap skripsi, tesis dan disertasi yang tidak dipublikasikan di dua perpustakaan PTN. Berdasarkan formulasi masalah yang telah ditetapkan akan diperoleh sejumlah 
hasil penelitian yang digunakan sebagai data studi primer.

Penelusuran artikel melalui google scholar dengan keyword kepemimpinan diperoleh hasil sejumlah 45.000. Sedangkan penelusuran menggunakan keyword kepemimpinan+budaya+organisasi diperoleh hasil sebanyak 20.900. Penelusuran melalui OPAC UPT Perpustakaan UNJ diperoleh 4732 koleksi tesis dan disertasi, sedangkan skripsi sebanyak 31.454 judul. Sementara itu penelusuran melalui Lontar UI diperoleh jumlah koleksi disertasi sebanyak 1379 disertasi, 34.765 tesis dan 57.406 skripsi.

Analisis data menggunakan analisis korelasi meta-analisis. Metaanalisis yang dilakukan adalah: 1) Data terkumpul berupa hasil penelitian korelasional terkait variabel yang diuji, dilakukan klasifikasi dan kodefikasi; 2) Menganalisis koreksi terhadap kesalahan pengambilan sampel (sampling error) dengan menghitung mean korelasi, menghitung varian, menghitung varian kesalahan sampel, dan dampak pengambilan sampel; 3)
Menganalisis kesalahan pengukuran baik pada variabel independen maupun variabel dependen dengan menghitung mean gabungan, menghitung korelasi populasi yang dikoreksi oleh kesalahan pengukuran, interval kepercayaan dan dampak variasi reliabilitas; dan 4) Menganalisis koreksi terhadap koefisien korelasi.

Berdasarkan kajian teori dan konstruk yang dibangun telah dirumuskan hipotesis penelitian $\left(\mathrm{H}_{1}\right)$. Adapun rumusan hipotesis statistik dalam penelitian ini adalah:

$\begin{array}{ll}\mathrm{H}_{0}: & { }^{\bar{r}} \mathrm{xy} \leq 0 \\ \mathrm{H}_{1}: & { }^{\bar{r}} \\ \mathrm{xy}>0\end{array}$

HASIL DAN PEMBAHASAN

Hasil penelusuran terhadap penelitian korelasional pengaruh kepemimpinan terhadap budaya organisasi baik yang dipublikasikan dan tidak dipublikasikan ditemukan 12 penelitian. Tabel 1 berikut ini memaparkan deskripsi singkat ke-12 penelitian

Tabel 1. Profile Penelitian Korelasional Pengaruh Kepemimpinan terhadap Budaya Organisasi (2010-2015)

\begin{tabular}{c|l|c|l|l|c}
\hline No. & \multicolumn{1}{|c|}{ Peneliti } & Tahun & \multicolumn{1}{c|}{ Subjek } & \multicolumn{1}{c}{ Lokasi } & Klasifikasi Dokumen \\
\hline 1. & Budi Hermawan & 2010 & Dosen PTN & Banten & Disertasi \\
\hline 2. & Sri Lelis Maryati & 2011 & Guru SMA & Indramayu & Tesis \\
\hline 3. & R. Pudyo Prayudi & 2012 & Widyaiswara & Jakarta & Disertasi \\
\hline 4. & $\begin{array}{l}\text { Benyamin } \\
\text { Situmorang }\end{array}$ & 2012 & $\begin{array}{l}\text { Kepala } \\
\text { Sekolah }\end{array}$ & Medan & Disertasi \\
\hline 5. & Nita Mulyani & 2012 & Guru SMAN & Bandung & Skripsi \\
\hline 6. & $\begin{array}{l}\text { Sjeddie Rianne } \\
\text { Watung }\end{array}$ & 2013 & $\begin{array}{l}\text { Mahasiswa } \\
\text { PTN }\end{array}$ & Manado & Disertasi \\
\hline 7. & Supriana & 2013 & Guru SMPN & Banjar - Jawa & Disertasi \\
\hline
\end{tabular}




\begin{tabular}{c|c|c|c|c|c}
\hline & & & Barat & Disertasi \\
\hline 8. & Zulkifli & 2014 & Dosen PTS & Pekan Baru & Disertasi \\
\hline 9. & Dedi Purwana E.S. & 2015 & $\begin{array}{c}\text { Ketua } \\
\text { Program } \\
\text { Studi }\end{array}$ & Jakarta & Disertasi \\
\hline 10. & Efendy Rasjid & 2015 & Dosen PTN & Manado & Disertasi \\
\hline 11. & Soetardjo Sayid & 2015 & Widyaiswara & Jakarta & Artikel Jurnal \\
\hline 12. & $\begin{array}{c}\text { Estefan Junaydi } \\
\text { dan Devie }\end{array}$ & 2015 & $\begin{array}{c}\text { Mahasiswa } \\
\text { PTS }\end{array}$ & Surabaya & \multicolumn{2}{|c|}{} \\
\hline
\end{tabular}

Dari 12 penelitian pada tabel 1 tampak bahwa kelompok subjek penelitian terdiri dari Dosen, Guru, Kepala Sekolah, Ketua Program Studi, Widyaiswara dan Mahasiswa. Berdasarkan Tabel 1 dapat diidentifikasi keragaman subjek penelitian sebagai berikut: 1) Dosen sebanyak 3 penelitian (25\%), Guru sejumlah 3 penelitian (25\%), Kepala Sekolah sebanyak 1 penelitian (8\%), Ketua Program Studi sejumlah 1 penelitian $(8 \%), \quad$ Widyaiswara sejumlah 2 penelitian (17\%), dan Mahasiswa sejumlah 2 penelitian $(17 \%)$. Dengan demikian dapat disimpulkan bahwa penelitian korelasional berkenaan dengan 2 variabel yang diteliti pada kurun waktu 2010-2015 didominasi tenaga pendidik Dosen dan Guru. Tabel 2 berikut ini memaparkan karakteristik sampel penelitian berdasarkan Jenis Pekerjaan.

Tabel 2. Karakteristik Sampel Penelitian Berdasarkan Jenis Pekerjaan

\begin{tabular}{c|c|c|c}
\hline Subjek & $\begin{array}{c}\text { Frekuensi } \\
\text { Absolut }\end{array}$ & $\begin{array}{c}\text { Frekuensi Relatif } \\
(\%)\end{array}$ & Frekuensi Kumulatif \\
\hline Dosen & 3 & 25 & 25 \\
\hline Guru & 3 & 25 & 50 \\
\hline Kepala Sekolah & 1 & 8 & 58 \\
\hline Ketua Program Studi & 1 & 8 & 66 \\
\hline Widyaiswara & 2 & 17 & 83 \\
\hline Mahasiswa & 2 & 17 & 100 \\
\hline Jumlah & 12 & $100 \%$ & \\
\hline Adapun karakteristik & rampel
\end{tabular}
pendidikan adalah sebagai berikut:

Tabel 3. Karakteristik Sampel Penelitian Berdasarkan Jenis Lembaga Pendidikan

\begin{tabular}{l|c|c|c}
\hline \multicolumn{1}{c|}{ Lembaga Pendidikan } & Frekuensi Absolut & $\begin{array}{c}\text { Frekuensi Relatif } \\
(\%)\end{array}$ & $\begin{array}{c}\text { Frekuensi } \\
\text { Kumulatif }\end{array}$ \\
\hline Politeknik & 1 & 8 & 8 \\
\hline Universitas & 5 & 42 & 50 \\
\hline SMP & 1 & 8 & 58 \\
\hline SMA & 2 & 17 & 75 \\
\hline SMK & 1 & 8 & 83 \\
\hline
\end{tabular}




\begin{tabular}{l|c|c|c}
\hline Balai Latihan Kerja & 2 & 17 & 100 \\
\hline Jumlah & 12 & $100 \%$ & \\
\hline
\end{tabular}

Karakteristik sampel penelitian pendidikan nampak bahwa 5 penelitian pada tingkat Universitas (42\%), selanjutnya 2 penelitian pada tingkat SMA (17\%), 2 penelitian pada tingkat Balai Latihan Kerja (17\%), dan selanjutnya pada tingkat politeknik $(8 \%)$, SMK (8\%) dan SMP (8\%). Dapat disimpulkan bahwa penelitian korelasional pengaruh kepemimpinan dan budaya organisasi lebih sering dilaksanakan di perguruan tinggi dalam kurun waktu 2010-2015.
Analisis Korelasi Meta Analisis

1. Penghitungan Koreksi Kesalahan Pengambilan Sampel Dari koreksi terhadap kesalahan pengambilan sampel (sampling error) dengan menghitung mean korelasi, menghitung varian, menghitung varian kesalahan sampel, dan dampak pengambilan sampel. Tabel berikut memaparkan akumulasi hasil penelitian korelasional kepemimpinan $(X)$ terhadap budaya organisasi $(\mathrm{X})$.

Tabel 4. Akumulasi Hasil Penelitian Korelasional Pengaruh Kepemimpinan terhadap Budaya Organisasi (2010-2015)

\begin{tabular}{|c|c|c|c|c|c|c|}
\hline \multirow[t]{2}{*}{ No } & \multirow[t]{2}{*}{ Subyek } & \multirow[t]{2}{*}{$\mathrm{n}$} & \multirow[t]{2}{*}{$r$} & \multirow[t]{2}{*}{$\mathrm{t}$} & \multicolumn{2}{|c|}{ Reliabiltas } \\
\hline & & & & & Variabel X & Variabel Y \\
\hline 1 & Dosen PTN & 100 & 0,430 & 3,860 & 0,960 & 0,975 \\
\hline 2 & Guru SMA & 168 & 0,859 & 5,987 & 0,947 & 0,978 \\
\hline 3 & Instruktur/ Widiaiswara & 135 & 0,490 & 1,989 & 0,905 & 0,926 \\
\hline 4 & Kepala Sekolah & 110 & 0,514 & 6,221 & 0,897 & 0,942 \\
\hline 5 & Guru SMAN & 73 & 0,572 & 5,875 & 0,676 & 0,844 \\
\hline 6 & Mahasiswa PTN & 73 & 0,778 & 38,800 & 0,946 & 0,905 \\
\hline 7 & Guru SMPN & 77 & 0,535 & 4,780 & 0,949 & 0,963 \\
\hline 8 & Dosen PTS & 251 & 0,540 & 10,020 & 0,971 & 0,951 \\
\hline 9 & Ketua Program Studi & 63 & 0,491 & 4,398 & 0,967 & 0,963 \\
\hline 10 & Dosen PTN & 75 & 0,485 & 4,735 & 0,976 & 0,967 \\
\hline 11 & Widyaiswara & 54 & 0,685 & 3,297 & 0,970 & 0,940 \\
\hline 12 & Mahasiswa PTS & 420 & 0,491 & 5,976 & 0,842 & 0,800 \\
\hline & Jumlah & 1599 & & & & \\
\hline
\end{tabular}

\section{1) Rerata Koefisien Korelasi}

Data pada tabel 4 menunjukkan koefisien korelasi $(r)$ yang beragam. Nilai koefisien $r$ yang terendah adalah 0,430 dan tertinggi sebesar 0,977.Untuk mengetahui koefisien korelasi sesungguhnya dari ke 12 


$$
\begin{aligned}
& \bar{r}=\frac{100(0,430)+168(0,859)+}{135(0,490)+\ldots+420(0,491)} \frac{1599}{159} \\
& =0,573
\end{aligned}
$$

Rata-rata jumlah subyek dari ke 12 hasil penelitian tersebut di atas adalah 133,25 atau dibulatkan menjadi 133 (Jumlah sampel (1599) : jumlah penelitian (12)). Hasil ratarata koefisien korelasi $=0,573$ tersebut di atas apabila diuji signifikansinya dengan jumlah subyek rata-rata sebesar 133 maka diketahuilah bahwa koefisien korelasi tersebut adalah sangat signifikan.

\section{2) Rerata Reliabiltas Variabel}

Untuk penghitungan koreksi terhadap koefisien korelasi yang ada, diperlukan penghitungan rerata reliablitas variabel kepemimpinan $(X)$ dan variabel budaya organisasi $(Y)$. Berdasarkan tabel 4, rerata reliabilitas variabel $x$ adalah sebagai berikut:

$$
\begin{aligned}
& \frac{100(0,960)+168(0,747)+}{135(0,905)+\ldots+420(0,842)} \\
\bar{r}_{x X} & =\frac{1599}{=} \\
= & 0,917
\end{aligned}
$$

Sedangkan rerata realiabilitas variabel $Y$ adalah:

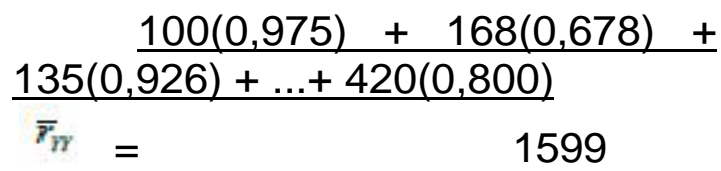

$$
=0,930
$$

\section{Penghitungan Kesalahan Peng- ukuran (Error of Measurement)}

\section{1) Koreksi Koefisien Korelasi}

Langkah selanjutnya adalah melakukan koreksi terhadap koefisien korelasi yang ada. Secara psikometrik diyakini bahwa setiap pengukuran adalah memuat adanya kesalahan atau error of measurement. Koefisien determinasi korelasi hipotetik antara obtained score dengan true score adalah sepadan dengan koefisien relibilitas atau dapat dinyatakan :

$$
\begin{aligned}
& r_{X X}=\rho_{X T}{ }^{2} \text { atau sama dengan } \\
& \sqrt{r_{x x}}=\rho_{x T}
\end{aligned}
$$

Maka koreksi terhadap koefisien korelasi dapat dilakukan dengan formula:

$$
r_{C}=\frac{r_{X Y}}{\sqrt{r_{X X}} \sqrt{r_{r Y}}}
$$

Telah diketahui bahwa koefisien korelasi antar dua variabel dipengaruhi oleh besaran reliabilitas alat ukur dari kedua variabel.Oleh karena itu reliabilitas dari ke dua variabel dipergunakan untuk mengoreksi besaran koefisien korelasi.Formula tersebut selanjutnya dikenakan pada koefisien korelasi hasil penelitian dari nomor satu hingga nomor 12. Untuk hasil penelitian nomor satu adalah :

0,430 


$$
r_{C, 444}=\sqrt{0,960} \sqrt{0,975}=
$$

Analog dengan hasil perhitungan hasil penelitian nomor satu tersebut di atas, maka dapat dilakukan untuk hasil-hasil penelitian selanjutnya, dan hasilnya dapat dilihat pada tabel berikut:

Tabel 5. Rekapitulasi Koreksi Koefisien Korelasi

\begin{tabular}{r|l|c|c|c|c|c|r}
\hline No & \multicolumn{1}{|c|}{ Subyek } & $\mathrm{n}$ & $\mathrm{r}$ & $\mathrm{t}$ & \multicolumn{2}{|c|}{ Reliabiltas } & \multirow{2}{*}{ Fic } \\
\hline & & & & & Variabel X & Variabel Y & \\
\hline 1 & Dosen PTN & 100 & 0,430 & 3,860 & 0,960 & 0,975 & 0,444 \\
2 & Guru SMA & 168 & 0,859 & 5,987 & 0,947 & 0,978 & 0,893 \\
\hline 3 & Instruktur/ Widiaiswara & 135 & 0,490 & 1,989 & 0,905 & 0,926 & 0,535 \\
\hline 4 & Kepala Sekolah & 110 & 0,514 & 6,221 & 0,897 & 0,942 & 0,559 \\
\hline 5 & Guru SMAN & 73 & 0,572 & 5,875 & 0,676 & 0,844 & 0,757 \\
\hline 6 & Mahasiswa PTN & 73 & 0,778 & 38,800 & 0,946 & 0,905 & 0,841 \\
\hline 7 & Guru SMPN & 77 & 0,535 & 4,780 & 0,949 & 0,963 & 0,560 \\
8 & Dosen PTS & 251 & 0,540 & 10,020 & 0,971 & 0,951 & 0,562 \\
\hline 9 & Ketua Program Studi & 63 & 0,491 & 4,398 & 0,967 & 0,963 & 0,509 \\
\hline 10 & Dosen PTN & 75 & 0,485 & 4,735 & 0,976 & 0,967 & 0,499 \\
\hline 11 & Widyaiswara & 54 & 0,685 & 3,297 & 0,970 & 0,940 & 0,717 \\
\hline 12 & Mahasiswa PTS & 420 & 0,491 & 5,976 & 0,842 & 0,800 & 0,598 \\
\hline
\end{tabular}

Keterangan: $r_{c}$ adalah correted correlation

Hasil corrected correlation pada tabel 5 menunjukkan bahwa seluruh hasil penelitian memiliki nilai koefisien korelasi signifikan dengan rerata $r_{\mathrm{c}}$ sebesar 0,623 .

\section{2) Varians Distribusi Koefisien Korelasi}

Telah diketahui bahwa rerata koefisien korelasi dari ke 12 penelitian adalah 0,573.Berdasarkan nilai rerata koefisien korelasi tersebut maka dapat dihitung varians distribusi korelasinya. Varians distribusi koefisien korelasi dapat dihitung dengan formula:

http://journal.unj.ac.id/unj/index.php/jpeb

$$
\begin{aligned}
\sigma_{r}{ }^{2}=\frac{\sum N_{i}\left(r_{i}-\bar{r}\right)^{2}}{\sum N_{i}} \\
=\frac{\frac{100(0,430-0,573)^{2}+168(0,859}{0,573)^{2}+\ldots+420(0,491}-}{0,573)^{2}} \\
=0,01736
\end{aligned}
$$

\section{3) Sampling Error Varians}

Setiap pengambilan sampel pada suatu penelitian selalu memuat adanya kesalahan yang disebabkan oleh karena pengambilan sampel tersebut atau diistilahkan dengan sampling error.Sampling error juga 
memiliki variansnya sendiri, dan untuk menentukan sampling error variance dapat digunakan formula sebagai berikut.

$$
\begin{aligned}
& \left(\sigma^{2} e\right)=\left(1-r^{2}\right)^{2} /(N-1) \\
= & \left(1-0,573^{2}\right)^{2} /(133-1) \\
= & 0,006749
\end{aligned}
$$

Penelitian sosial memiliki kelemahan dalam error of measurement. Estimasi varians dari populasi korelasi adalah sama dengan varians koefisien korelasi yang sesungguhnya ditambah

Tabel 6. Lembar Kerja Meta Analisis

\begin{tabular}{r|l|c|c|c|c|c|c}
\hline & & & & \multicolumn{2}{|c|}{ Reliabiltas } & & \\
\cline { 5 - 6 } No & \multicolumn{1}{|c|}{ Subyek } & $\mathbf{n}$ & $\mathbf{r}$ & Variabel X & Variabel Y & $\mathbf{a}$ & $\mathbf{b}$ \\
\hline & & & & & & & \\
1 & Dosen PTN & 100 & 0.430 & 0.960 & 0.975 & 0.980 & 0.987 \\
\hline 2 & Guru SMA & 168 & 0.859 & 0.947 & 0.978 & 0.973 & 0.989 \\
\hline 3 & Instruktur/ Widiaiswara & 135 & 0.490 & 0.905 & 0.926 & 0.951 & 0.962 \\
\hline 4 & Kepala Sekolah & 110 & 0.514 & 0.897 & 0.942 & 0.947 & 0.971 \\
\hline 5 & Guru SMAN & 73 & 0.572 & 0.676 & 0.844 & 0.822 & 0.919 \\
\hline 6 & Mahasiswa PTN & 73 & 0.778 & 0.946 & 0.905 & 0.973 & 0.951 \\
\hline 7 & Guru SMPN & 77 & 0.535 & 0.949 & 0.963 & 0.974 & 0.981 \\
\hline 8 & Dosen PTS & 251 & 0.540 & 0.971 & 0.951 & 0.985 & 0.975 \\
\hline 9 & Ketua Program Studi & 63 & 0.491 & 0.967 & 0.963 & 0.983 & 0.981 \\
\hline 10 & Dosen PTN & 75 & 0.485 & 0.976 & 0.967 & 0.988 & 0.983 \\
\hline 11 & Widyaiswara & 54 & 0.685 & 0.970 & 0.940 & 0.985 & 0.970 \\
\hline 12 & Mahasiswa PTS & 420 & 0.491 & 0.842 & 0.800 & 0.918 & 0.894 \\
\hline & Average (Ave) & $\mathbf{1 3 3}$ & $\mathbf{0 . 5 7 3}$ & $\mathbf{0 . 9 1 7}$ & $\mathbf{0 . 9 3 0}$ & $\mathbf{0 . 9 5 7}$ & $\mathbf{0 . 9 6 4}$ \\
\hline
\end{tabular}

Keterangan:

a. $\underset{\text { koefisien reliabilitas variabel }}{\mathrm{a}=a=\sqrt{r_{X X}}}$ (akar dari kepemimpinan $(\mathrm{X})$ dan $\mathrm{b}=$ $b=\sqrt{r_{Y Y}} \quad$ (akar dari koefisien reliablitas variabel budaya organisasi ( $\mathrm{Y})$. 


$$
\begin{aligned}
& \bar{A}=A v e(a) A v e(b) \\
& =(0,957)(0,964) \\
& =0,922
\end{aligned}
$$

Sehingga dapat ditentukan rata-rata yang belum dikoreksi yaitu:

$$
\begin{aligned}
& \bar{D}-A_{\nu}\left(\rho_{i}\right)-\frac{\bar{r}}{\bar{A}} \\
= & 0,573 / 0,922 \\
= & 0,621
\end{aligned}
$$

Jumlah kuadrat koefisien variasi dapat diperoleh dengan formula:

$$
\begin{gathered}
V=\left[\frac{S D_{a}}{\text { Avea }}\right]^{2}+\left[\frac{S D_{b}}{\text { Aveb }}\right]^{2} \\
={ }^{2}[0,047 / 0,957]^{2}+ \\
=0,00334
\end{gathered}
$$

Varians dari variasi ketidaksempurnaan penelitian adalah:

$$
\begin{gathered}
S_{2}{ }^{2}=\bar{\rho}^{2} \cdot \bar{A}^{2} \cdot V \\
= \\
(0,621)^{2} \cdot(0,922)^{2} \cdot(0,00334) \\
=0,00110
\end{gathered}
$$

Dari hasil tersebut dapat diperoleh koefisien korelasi yang sebenarnya, yaitu:

$$
\begin{aligned}
\operatorname{Var}(\rho) & =\frac{\operatorname{Var}\left(\rho_{0}\right)-\bar{\rho}^{2} \bar{A}^{2} \cdot V}{\bar{A}^{-}}=\left[\frac{\operatorname{Var}\left(\rho_{0}\right)-S_{2}{ }^{2}}{\bar{A}}\right] \\
& =\frac{0,01061-0,00110}{0,922} \\
& =0,010315
\end{aligned}
$$

http://journal.unj.ac.id/unj/index.php/jpeb
Jadi standar deviasi dari effect size korelasi, atau disebut juga standar deviasi dari koefisien korelasi yang betul adalah $\sqrt{ } 0,010315=$ 0,101565 . Dengan demikian diperoleh hasil akhir studi, hasil korelasi yang sesungguhnya mempunyai rata-rata 0,573 dan Standar Deviasi sebesar 0,101565. Dikarenakan rata-rata koefisien korelasi dari ke 12 penelitian lebih besar dari 0 , maka uji hipotesis membuktikan menerima $\mathrm{H}_{1}$ dan menolak $\mathrm{H}_{0}$. Kesimpulan dari kajian meta analisis ini adalah terdapat pengaruh positif kepemimpinan terhadap budaya organisasi pada lembaga pendidikan di Indonesia.

\section{KESIMPULAN DAN SARAN}

Berdasarkan hasil analisis dan pengujian hipotesis, diperoleh kesimpulan sebagai berikut: (1) Kepemimpinan berpengaruh positif terhadap budaya organisasi. Penerapan gaya kepemimpinan yang kuat dapat meningkatkan kualitas budaya organisasi pada lembaga pendidikan di Indonesia dengan $\bar{r}=$ 0,573 dan corrected correlation ( $r_{\mathrm{c}}$ )sebesar 0,623; (2) Secara umum, ke 12 penelitian korelasional pengaruh kepemimpinan terhadap budaya organisasi menunjukkan hasil koefisien korelasi yang konsisten; (3) Perbedaan korelasi dari ke 12 penelitian korelasional disebabkan oleh dampak kesalahan pengambilan sampel $\left(o^{2}{ }_{e}\right)$ sebesar0,006749 dengan estimasi 
varians populasi $\left(\sigma_{\infty}^{\prime}\right)$ sebesar 0,01061, dan (4) Analisis dalam meta analisis didasarkan pada informasi artifak sebagai kriteria untuk memahami mengapa terdapat perbedaan hasil penelitian mengenai suatu topik yang sama. Ketidaksempurnaan atau artifak-artifak itulah yang dikoreksi. Jika tidak, akan menimbulkan bias estimasi terhadap hasil penelitian yang sesungguhnya.

Berdasarkan pembahasan dan kesimpulan penelitian dapat dirumuskan beberapa saran sebagai berikut: (1) Hasil penelitian dengan pendekatan meta analisis ini menekankan pentingnya kepemimpinan dalam meningkatkan kualitas budaya organisasi. Kepemimpinan yang efektif akan menyebabkan terjadinya peningkatan kualitas budaya organisasi; (2) Hasil penelitian ini dapat juga dimanfaatkan oleh lembaga pendidikan untuk menggali dan mengembangkan kebijakan yang tepat terkait upaya untuk meningkatkan kualitas kepemimpinan dan budaya organisasi dalam pencapaian tujuan organisasi, dan (3) Penelitian ini dapat dijadikan landasan empiris bagi penelitianpenelitian selanjutnya dengan menambahkan durasi waktu dan site penelitian yang berbeda.

\section{DAFTAR PUSTAKA}

Abbasi, E. d.-M. (2013). The Role of Transformational Leadership, organizational culture and organizational learning in Improving the Performance of Iranian Agricultural Faculties. Higher Education, Vol. 66, 505519.

Balyer, A. (2012). Transformational Leadership Behaviors of School Principals: A Qualitative Research Based on Teachers' Perceptions. International Online Journal of Educational Sciences, Vol. 4 (3), 581-591.

Bass, B. M. (2006). Transformational Leadership (Second Edition ed.). New Jersey: Lawrence Erlbaum Associate Inc.

Borenstein, M. e. (2009). Introduction to Meta-Analysis. UK: John Willey \& Sons.

Bush, T. d. (2005). Leading and Managing People in Education. London: Sage Publications.

Colquitt, J. A. (2015). Organizational Behavior Improving Performance and Commitment in the Workplace (Fourth Edition ed.). New York: McGraw Hill.

Daft, R. L. (2008). The Leadership Experience (Fourth Edition ed.). Ohio: Thomson SouthWestern.

Heneman III, H. G. (2015). Staffing Organizations (Eight Edition ed.). New York: McGraw-Hill. 
Hughes, R. L. (2009). Leadership. New York: McGraw-Hill Companies.

Hunter, J. E. (2004). Methods of Meta-Analysis - Correcting Error and Bias in Research Findings (Second Edition ed.). London: Sage Publications.

Ivancevich, J. M. (2008). Organizational Behavior and Management (Eighth Edition ed.). New York: McGraw-Hill.

Jones, G. R. (2013). Organizational Theory, Design and Change (Seventh Edition ed.). England: Pearson.

Korkmaz, M. (2007). The Effects of Leadership Styles on Organizational Health. Educational Research Quarterly, Vol. 30, No. 3, 2254.

Kreitner, R. d. (2011). Organizational Behavior (Ninth Edition ed.). New York: McGraw- Hill.

Luthans, F. (2011). Organizational Behavior: An Evidence-based Approach (Twelfth Edition ed.). New York: McGraw-Hill/ Irwin.

Mullins, L. J. (2010). Management and Organizational Behavior (Ninth Edition ed.). England: Pearson Education Limited.

Robbins, S. P. (2007). Organizational Behaviour (Twelfth Edition ed.). New Jersey: Pearson Prentice Hall.

Robbins, S. P. (2009). Management (Tenth Edition ed.). New Jersey: Prentice-Hall.
Schein, E. H. (2010). Organizational Culture and Leadership (Fouth Edition ed.). San Francisco: John Wiley \& Sons, Inc.

Smith, E. E. (2009). The Relationship Between Organizational Culture, Societal Culture, And Leadership Styles. Published Dissertation, Capella University.

Weihrich, H. d. (2005). Management: A Global Perspective (11th ed ed.). Singapore: McGraw-Hill. 